\title{
Application of the Adverse Outcome Pathway Framework to Risk Assessment for Predicting Carcinogenicity of Chemicals
}

REVIEW

\author{
Doo Seok Kang ${ }^{1}$, Jun Hyuek Yang ${ }^{1}$, Hyun Soo Kim ${ }^{1}$, Bon Kon Koo ${ }^{1}$, Cheol Min Lee ${ }^{2}$, Yeon-Soon Ahn ${ }^{3}$, Jong-Hyeon Jung ${ }^{4}$, \\ Young Rok Seo ${ }^{1}$
}

${ }^{1}$ Institute of Environmental Medicine for Green Chemistry, Department of Life Science, Dongguk University Biomedi Campus, Goyang, ${ }^{2}$ Department of Chemical and Biological Engineering, College of Natural Science and Engineering, Seokyeong University, Seoul, ${ }^{3}$ Department of Preventive Medicine and Institute of Occupational and Environmental Medicine, Yonsei University Wonju College of Medicine, Wonju, ${ }^{4}$ Faculty of Health Science, Daegu Haany University, Gyeongsan, Korea

\begin{abstract}
As industry develops in modern society, many chemicals are being used. The safety of chemicals is an important issue because humans are constantly exposed to chemicals throughout their daily life. Through a risk assessment, the hazardous human effects of chemicals can be identified. Recently, the adverse outcome pathway (AOP) framework has been used to predict the adverse effects of chemicals. As a conceptual framework for organizing existing biological knowledge, the AOP consists of a molecular initiating event, key events, and an adverse outcome. These independent elements represent biological responses and are connected by key event relationships. This AOP framework provides intuitive hazard identification that can be helpful for carcinogenic risk assessment of chemicals. In this review, we introduce the application of the AOP framework to risk assessment for predicting carcinogenicity of chemicals and illustrate the utility of this approach for cancer prevention.
\end{abstract}

(J Cancer Prev 2018;23:126-133)

Key Words: Chemical safety, Adverse outcome pathways, Carcinogenesis, Risk assessment

\section{INTRODUCTION}

As technology develops in modern society, numerous chemicals are being used. Globally, more than 15 million chemicals are commercially available. ${ }^{1}$ Humans are exposed to chemicals in everyday life through everyday use or accident. Despite their widespread use, the effects of many chemicals on human health are not well known. Commensurate with the growing interest in the safety of chemicals, the formal safety evaluation of chemicals is becoming an important issue. Given the extensive use and diversity of chemicals, there are also many risks associated with chemical accidents. The chemical accidents reported worldwide between 1970 and 1998 resulted in more than 100,000 casualties. ${ }^{1}$
Due to insufficient management or natural disaster, chemical accidents have occurred through leakage, fire, and explosion., ${ }^{2.3}$ Because chemicals are stored in huge reservoirs, factories, and transport vehicles, ${ }^{2}$ if a chemical accident occurs, the scale and extent of damage can be considerable. To manage chemicals and chemical accidents, governments and other relevant institutions need to know the human health effects of chemicals.

Chemical properties are typically classified as flammability, corrosivity, reactivity, and toxicity. ${ }^{4}$ Due to these chemical properties, chemicals can affect the human body and the environment acutely or chronically. Flammable, corrosive, and reactive chemicals pose a primary threat to victims who are near the site of a chemical accident, through high temperature and $\mathrm{pH}$. In

Received September 11, 2018, Revised September 25, 2018, Accepted September 27, 2018

Correspondence to: Young Rok Seo

Institute of Environmental Medicine for Green Chemistry, Department of Life Science, Dongguk University Biomedi Campus, 32 Dongguk-ro, Ilsandong-gu, Goyang 10326, Korea

Tel: +82-31-961-5172, E-mail: seoyr@dongguk.edu, ORCID: Young Rok Seo, https://orcid.org/0000-0002-4093-4073

Copyright (ㄷ) 2018 Korean Society of Cancer Prevention

(c) This is an Open Access article distributed under the terms of the Creative Commons Attribution Non-Commercial License (http://creativecommons.org/icenses/by-nc/4.0) which permits unrestricted non-commercial use, distribution, and reproduction in any medium, provided the original work is properly cited. 
addition to these primary threats, toxicity can be considered as a secondary threat. Chemical toxicities can not only cause immediate damage to our bodies but also cause delayed, invisible adverse effects, such as DNA damage and mutation. Ultimately, these long-term effects of chemical toxicity can increase the probability of carcinogenesis. ${ }^{5,6}$ Risk assessment is considered to be an important means of evaluating the overall hazardous human impact of chemicals.

Risk assessment of a chemical involves understanding the nature, magnitude, and probability of its potential adverse health or environmental effects. ${ }^{7}$ Risk assessment can be used to assess chemical safety and establish relevant regulations, by identifying how dangerous a chemical may be at certain concentrations and how it ultimately affects the human body. However, many risk assessors have faced the problem that traditional methods to evaluate chemical toxicity are not adequate for the ever-increasing number of chemicals. ${ }^{8}$ Recently, the adverse outcome pathway (AOP) concept has been applied as a pragmatic tool in toxicology to determine the human effects of chemicals. ${ }^{9}$

The AOP is a conceptual construct for description on a biological level relevant to risk assessment. ${ }^{10}$ In 2007, the National Research Council suggested a vision for the future of toxicity testing in 'Toxicity Testing in the 21st Century'. ${ }^{11}$ This report emphasizes the need to develop a rapid and accurate toxicity assessment while maximizing the use of existing knowledge. In keeping with this trend, the AOP has emerged to fill the need for an efficient, predictive toxicity assessment method applicable to numerous chemicals that can reduce animal testing and save time and cost. ${ }^{8}$ Because AOPs can provide an intuitive understanding of the hazardous effects of chemicals, they can be helpful for risk assessment. In this review, we introduce the application of AOPs to risk assessment of chemicals, especially carcinogenic risk assessment. We expect that the AOP will be adopted as a future-oriented method that ultimately predicts and prevents cancer, as an apical endpoint of the adverse effect of chemicals.

\section{OVERVIEW OF RISK ASSESSMENT FOR PREDICTING CARCINOGENICITY OF CHEMICALS}

The purpose of risk assessment is to evaluate qualitative and quantitative information about hazards. ${ }^{12}$ For a given substance or element that can cause harm, a hazard is the source of risk, that is, the combination of the probability and magnitude of an adverse effect. ${ }^{13}$ Chemicals are continually being made and used, and because any of them could be a potential hazard, many international organizations disseminate extensive information about chemicals such as their properties, structure, safety, toxicity, and usage in risk assessment databases (e.g., PubChem, TOXNET, and INCHEM). Nonetheless, this information remains insufficient to fully assess the safety of many chemicals. ${ }^{14}$

Generally, risk assessment is conducted through four processes: hazard identification, dose-response assessment, exposure assessment, and risk characterization. The United States Environmental Protection Agency (US EPA) defines these four steps (Fig. 1). ${ }^{15}$ First, hazard identification is the process that examines whether chemicals have harmful effects on humans or ecosystems in certain situations. Key components of hazard identification involve analyzing the mode of action (MOA) and evaluating the weight of evidence (WOE). Dose-response assessment examines the mathematical relationship between exposure degree and toxic effect. Typically, as the dose increases, so does the measured response. In a non-linear dose-response that has a threshold value for the response, values such as no-observed-adverse-effect level, lowest-observed-adverse-effect level, benchmark dose, and reference dose are mathematically calculated. In a linear dose-response that has no threshold, cancer risk and slope factor are considered. Exposure assessment examines the frequency, duration, and levels of exposure to the chemical. Considering the range of exposure, this process quantifies the exposure. Lastly, risk characterization derives conclusions about the chemical's risk, by integrating previous

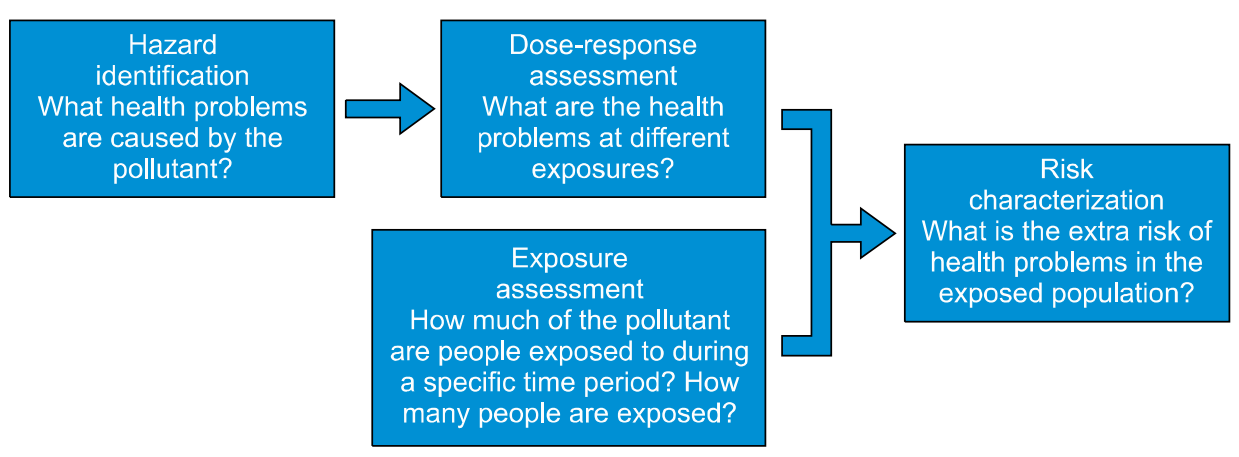

Figure 1. The 4 steps of the risk assessment process. The risk assessment consists of hazard identification, dose-response assessment, exposure assessment, and risk characterization. The text and figure are adopted from the United States Environmental Protection Agency (https:// www.epa.gov/risk/human-health-riskassessment). 
processes and provides a basis for policy-making for relevant chemicals. Chemical risk assessment is also based on mathematical and statistical models concerning biochemical and physiological factors, such as physiologically-based toxicokinetic modeling with Absorption, Distribution, Metabolism, and Excretion data generated by in vitro and in vivo experiments and quantitative structure-activity relationship tools. ${ }^{16,17}$

Human health effects caused by hazardous chemicals are diverse, depending on the exposure conditions. ${ }^{18}$ Except for chemical accidents that occur with low probability, though of course important, we focus on the effects of continuous exposure to chemicals in our daily life. Humans are exposed to chemicals in the environment through inhalation, ingestion, and dermal contact. $^{14}$ For example, from atmospheric pollutants, tobacco smoke, fine dust, workplace exposure, contaminated water, crops exposed to pesticides, drugs, cosmetics, and other sources, humans are chronically exposed to chemicals. Chronic exposure to chemicals can induce chronic toxicity, which may have a delayed adverse effect. ${ }^{19}$ Accumulation of delayed adverse effects in the body over a long time can induce genotoxic or nongenotoxic damage, by increasing genetic instability which increases the likelihood of developing cancer as an endpoint. 5,6,20,21 Various cellular abnormalities resulting from genetic or epigenetic alterations can occur in the carcinogenesis process. ${ }^{5}$ Because of this, the substances or stressors that can cause cancer are termed carcinogens. ${ }^{22}$ Several international organizations determine and classify carcinogens. For example, the International Agency for Research on Cancer classifies carcinogens into 5 stages $^{23}$ : Group 1 substances are carcinogenic to humans, Group 2A substances are probably carcinogenic to humans, Group 2B substances are possibly carcinogenic to humans, and the remaining groups relatively do not imply the carcinogenicity. As of the last update, 120 substances were classified as "carcinogenic to humans" (30
July 2018). Importantly, it should be understood that carcinogens may not cause cancer in all cases because the risk of cancer varies from substance to substance and depends on the exposure duration and intensity, and on each person's genetic makeup. 22,24

For years, many researchers have studied the concentration and other aspects of chemical exposure that cause adverse effects in the human body. ${ }^{25,26}$ Numerous risk assessment animal and epidemiology studies about chemical exposure dose-response have been reported. ${ }^{27-29}$ To economize time and cost along with the social atmosphere that sublates animal experiments, researchers have tried to improve chemical risk assessment methods and models.

\section{DEFINITION OF ADVERSE OUTCOME PATHWAY}

An AOP consists of a molecular initiating event (MIE), key events (KEs), key event relationships (KERs), and an adverse outcome (AO) (Fig. 2A). The MIE is an initial point of the AOP, representing the chemical interaction at the molecular level, such as ligand-receptor binding or DNA binding. KEs are biological changes triggered by the MIE at diverse levels of biological organization (cell, tissue level, or higher). As a specialized type of $\mathrm{KE}$, the $\mathrm{AO}$ represents a typical endpoint of biologic perturbation resulting from the MIE and is considered in risk assessment or regulatory decision-making. $\mathrm{MIE}, \mathrm{KEs}$, and $\mathrm{AO}$ are connected by a unidirectional arrow called the KER. The KER means the causal or predictive interaction between upstream and downstream KEs, and thereby facilitates inference or extrapolation of the state of downstream KEs from upstream KEs. ${ }^{30}$ Each element of the AOP should be based on the WOE meeting the Bradford Hill criteria. $^{31,32}$ WOE is the concept of using information from independent sources to provide evidence to meet the information

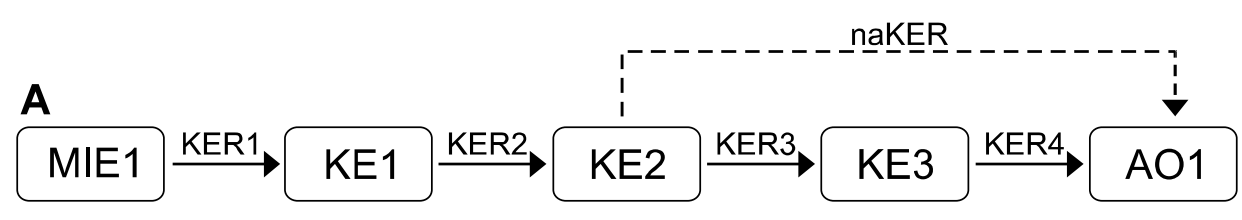

B

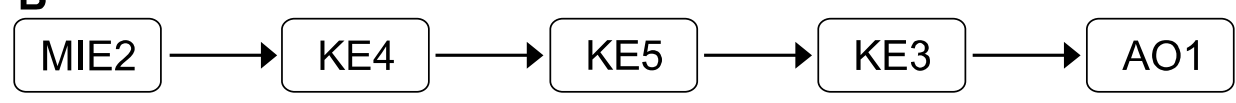

Figure 2. Schematic adverse outcome pathway (AOP) framework. (A) The AOP consist of a molecular initiating event (MIE), key event (KE), key event relationship (KER), and an adverse outcome (AO). Arrows indicate KERs and a dotted arrow is the naKER, that is, the non-adjacent (indirect) KER. Basically, a KER is the relationship between the two adjacent KEs, but the relationship between non-adjacent KEs is also possible. One AOP has one MIE and AO, and there is no limit to the number of KE and KER. (B) Since each component of an AOP exists independently, even different AOPs can contain the same component. Arrows also mean KER and the indication is omitted for convenience. 
requirements. ${ }^{33}$ One AOP should have one MIE and one AO, but there is no limitation to the number of KEs that are intermediate steps; also, each KE can be included in other AOPs (Fig. 2B).

The AOP describes the causal relationship of the cascade of biological responses at various biological levels caused by a stressor, leading to the $\mathrm{AO} .^{9,10,34}$ Any type of information associated with a biological reaction can be applied to the AOP (e.g., in vivo data, in vitro data, -omics data, and biomarkers). ${ }^{31}$ Therefore, the AOP is not static; it is a living document because existing information can become more accurate and change as the techniques used to observe biological reactions develop. ${ }^{34}$ Since the AOP is represented by a simple frame, it is intuitively easy to understand the adverse effects of chemicals. The AOP concept is not revolutionary; rather, it is the evolution of previously scattered concepts associated with toxic mechanisms. ${ }^{10,35}$

\section{CURRENT STATE OF THE ADVERSE OUTCOME PATHWAY}

Since the first AOP concept was proposed by Ankley et al. ${ }^{10}$ in 2010, there have been 243 AOPs and 1800 KEs registered as of August 2018. This AOP information is accessed freely in the Adverse Outcome Pathway-Knowledge Base (AOP-KB), which is the main AOP database managed by the Organization for Economic Co-operation and Development (OECD). To develop AOPs and to share and discuss related information among AOP developers, the OECD launched AOP-KB with collaboration from the US EPA, the European Commission's Joint Research Center, and the US Army Engineer Research and Development Center. ${ }^{36}$

The AOP-KB consists of AOP-Wiki, Effectopedia, Intermediate Effects DB, and AOP Xplorer. ${ }^{36}$ AOP-Wiki provides a system that organizes the available knowledge and published research information about each of the AOPs, KEs, KERs, and Stressors. Effectopedia is a modeling platform designed for development and application of AOPs. It provides quantitative information on AOP elements using experimental data. Currently, a beta version of Effectopedia is available. The Intermediate Effects DB treats chemical data and informs the process by which chemicals cause MIE or KEs. AOP Xplorer is a computational tool for graphical representation of AOPs. The Intermediate Effects DB and AOP Xplorer are currently being developed. All four systems share information via the AOP-KB Hub. Since each element in the AOP-KB is arranged separately and independently, the AOP-KB is useful for the development of AOPs and their application in diverse studies. $^{34}$

The OECD provides comprehensive management for AOP development and evaluation. ${ }^{30}$ The development of AOPs is overseen by the OECD Extended Advisory Group on Molecular Screening and Toxicogenomics (EAGMST), and AOP Wiki is managed by the Society for the Advancement of Adverse Outcome Pathways, under the guidance of the EAGMST. ${ }^{37}$ Since the first AOP titled "The Adverse Outcome Pathway for Skin Sensitisation Initiated by Covalent Binding to Proteins" was presented by the OECD, several reports and guidelines about AOP have been published. The OECD provides eight AOP-related publications and lists 60 projects in its AOPs development

Table 1. Components of AOP 46

\begin{tabular}{ll}
\hline \multicolumn{1}{c}{ Component } & \\
\hline MIE & Formation of pro-mutagenic DNA adducts \\
KE1 & Insufficient repair or mis-repair of pro-mutagenic DNA adducts \\
KE2 & Induced mutation in cancer critical genes \\
KE3 & Cellular proliferation, clonal expansion of mutant cells, and progression to form AHF \\
AO & Hepatocellular carcinoma \\
pre-MIE & Metabolism of AFB1 leads to formation of pro-mutagenic DNA adducts \\
KER1 & pro-mutagenic DNA adducts lead to insufficient repair or mis-repair of pro-mutagenic DNA adducts \\
KER2 & Insufficient repair or mis-repair of pro-mutagenic DNA adducts leads to induced mutation in cancer critical gene \\
KER3 & Induced mutation in cancer critical gene leads to cell proliferation and clonal expansion to form AHF \\
KER4 & Cell proliferation and clonal expansion to form AHF lead to HCC \\
naKER1 (MIE to KE2) & Formation of pro-mutagenic DNA adducts leads to induced mutation in cancer critical gene \\
naKER2 (MIE to KE3) & Formation of pro-mutagenic DNA adducts leads to cell proliferation and clonal expansion to form AHF \\
naKER3 (MIE to AO) & Formation of pro-mutagenic DNA adducts leads to HCC \\
naKER4 (KE2 to AO) & Induced mutation in cancer critical gene leads to HCC \\
\hline
\end{tabular}

AOP, adverse outcome pathway; MIE, molecular initiating event; KE, key event; AO, adverse outcome; KER, key event relationship; AHF, Altered Hepatic Foci; AFB1, aflatoxin B1; HCC, hepatocellular carcinoma. ${ }^{a}$ pre-MIE is a term we use randomly. There is no term to describe the relationship between the stressor and induction of a MIE because the first KER is defined as the relationship between the MIE and KE1. 
programme workplan as of August $2018 .^{38}$

\section{PREDICTION OF CARCINOGENICITY USING THE ADVERSE OUTCOME PATHWAY}

In this part, to illustrate carcinogenic risk assessment using $\mathrm{AOP}$, we describe the AOPs related to carcinogenesis that are currently developed or under development in the AOP-KB. The two examples of AOP are AOP 46 and AOP 220. These two AOPs have definitive MIE and carcinoma as AO. These are under EAGMST review status and are open for citation and comment. Predicting the adverse effects induced by carcinogens using AOP presents important points for prevention and treatment of cancer.

\section{Example 1: AOP $46^{39-41}$}

AOP 46 is titled "Mutagenic Mode-of-Action leading to Hepatocellular Carcinoma (HCC)". This AOP presents the mutagenic MOA for cancer by aflatoxin B1 (AFB1). AFB1 is considered to have a mutagenic MOA for HCC. The mutagenic MOA involves chemicals that induce mutation in a critical cancer gene, which is distinct from other MOAs for cancer. ${ }^{42,43}$ In this case, the mutation in the critical cancer gene is a consequence of pro-mutagenic DNA adducts induced by AFB1. AFB1 produces metabolites, one of which is the exo-8,9-epoxide that is an important reactive metabolite forming pro-mutagenic DNA adducts by binding to nuclear DNA. The most definitive evidence that a chemical has a mutagenic MOA is the demonstration that

A

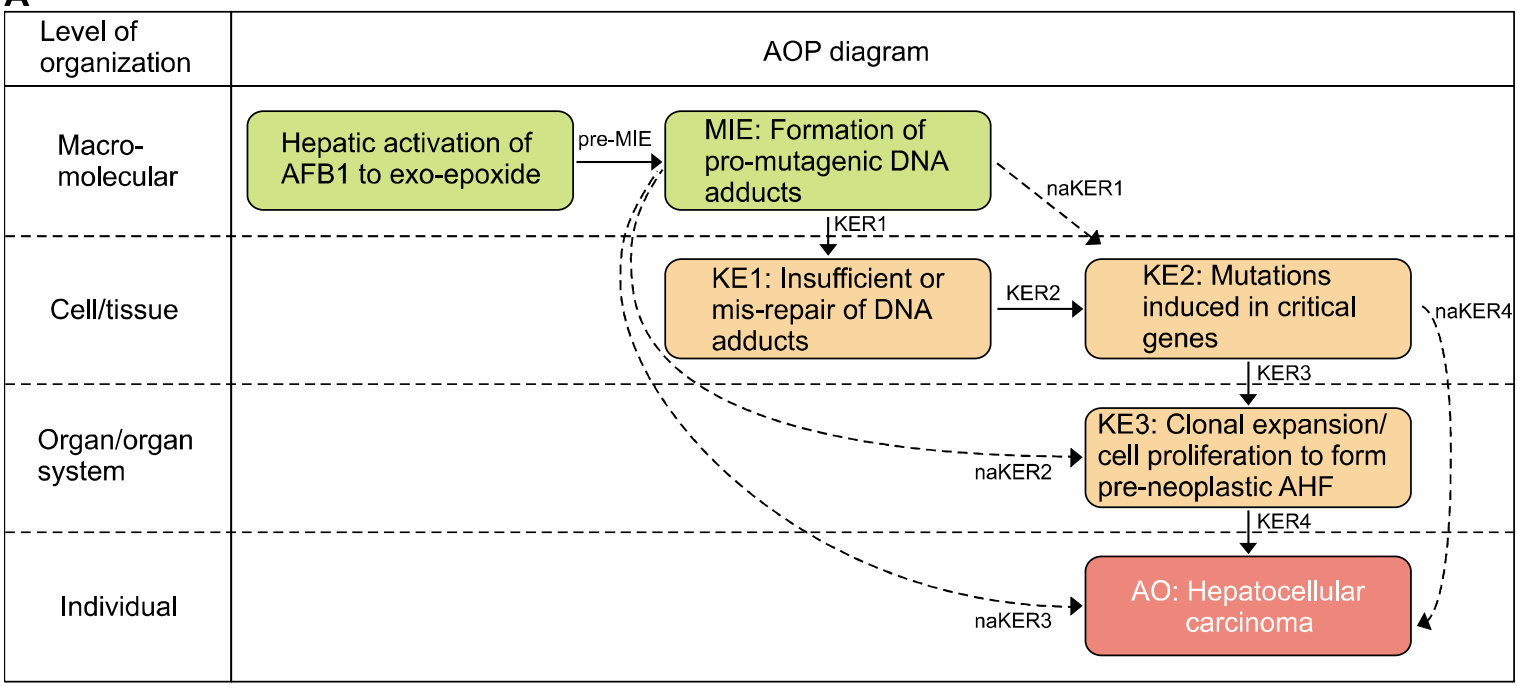

B

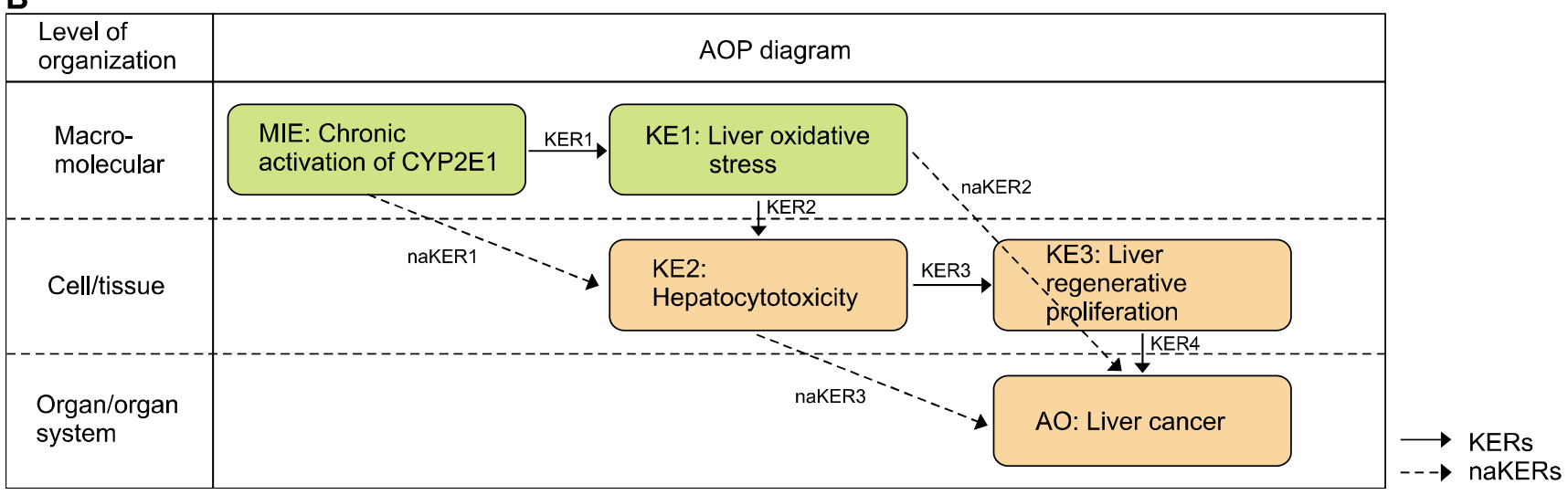

Figure 3. Carcinogenic adverse outcome pathway (AOP) examples. (A) The graphical representation of AOP 46 is adopted from the AOP-Wiki (https://aopwiki.org/aops/46). This AOP illustrates the process by which aflatoxin B1 (AFB1) causes hepatocellular carcinoma at various levels of biological organization. (B) The graphical representation of AOP 220 is adopted from the AOP-Wiki (https://aopwiki.org/aops/220). This AOP illustrates the process of liver cancer caused by the chronic activation of CYP2E1 at various levels of biological organization. MIE, molecular initiating event; KER, key event relationship; KE, key event; AO, adverse outcome; AHF, Altered Hepatic Foci. 
the chemical can induce a specific gene mutation frequently observed in a particular cancer. ${ }^{44} \mathrm{~A}$ specific mutation of codon 249 in the $p 53$ gene is often seen in AFB1-induced human HCC. This mutation is considered an important KE in AFB1-induced human HCC and provides a high correlation of AFB1 with HCC. Several factors associated with HCC include AFB1 exposure, infection of hepatitis $B$ virus or hepatitis $C$ virus, and alcohol use. ${ }^{45} \mathrm{~A}$ common feature of HCC is the oxidative damage in the liver, regardless of etiology. ${ }^{46} \mathrm{HCC}$ is considered an adverse effect endpoint in many hazard identifications. For example, the US EPA provides 111 cases of hazard identification associated with HCC. This AOP includes a series of components (Table 1), ${ }^{39}$ and is graphically represented in Figure 3A.

\section{Example 2: AOP $220^{47}$}

AOP 220 is titled "Chronic CYP2E1 Activation Leading to Liver Cancer". This AOP presents the process of liver cancer caused by chronic CYP2E1 activation. CYP2E1 is a member of the cytochrome P450 monooxygenases that catalyzes the oxidation of numerous low-molecular-weight xenobiotics, resulting in oxidative stress. Monooxygenation and the accompanying oxidative stress caused by CYP2E1 activation can induce hepatotoxicity, leading to liver cancer. CYP2E1 activates its substrates, generating electrophilic metabolites that are characteristic of carcinogens ${ }^{48}$ and produces reactive oxygen species that are important sources of cytotoxicity and oxidative lesions of DNA. ${ }^{49}$ Although the liver has a regenerative capacity through cellular proliferation that is

Table 2. Components of AOP 220

\begin{tabular}{ll}
\hline \multicolumn{1}{c}{ Component } & \multicolumn{1}{c}{ Description } \\
\hline MIE & Activation of CYP2E1 in the liver \\
KE1 & Oxidative stress \\
KE2 & Hepatocytotoxicity \\
KE3 & Hepatocellular regenerative proliferation \\
AO & Liver cancer \\
KER1 & Activation of CYP2E1 in the liver leads to \\
& oxidative stress \\
KER2 & Oxidative stress leads to \\
& hepatocytotoxicity \\
KER3 & Hepatocytotoxicity leads to hepatocellular \\
& regenerative proliferation \\
KER4 & Hepatocellular regenerative proliferation \\
& leads to liver cancer \\
naKER1 (MIE to KE2) & Activation of CYP2E1 in the liver leads to \\
& hepatocytotoxicity \\
naKER2 (KE1 to AO) & Oxidative stress leads to liver cancer \\
naKER3 (KE2 to AO) & Hepatocytotoxicity leads to liver cancer \\
\hline
\end{tabular}

AOP, adverse outcome pathway; MIE, molecular initiating event; $\mathrm{KE}$, key event; $\mathrm{AO}$, adverse outcome; KER, key event relationship. protective against injury, under chronic CYP2E1 activation, uncontrolled cellular proliferation causes carcinogenesis. In this AOP, carbon tetrachloride, chloroform, and furan were used as liver carcinogens, to profile the effect of chronic CYP2E1 activation. Because there are more than 80 CYP2E1 substrates known, exposure to these substances can be relatively common. CYP2E1 is well-studied and it is related to the metabolism of many substrates, so this AOP provides broadly-applicable information about the harmful effect of these substrates. This AOP includes a series of components (Table 2), ${ }^{47}$ and is graphically represented in Figure 3B.

Through these two examples of AOP, we illustrate the importance of understanding the early stages of the AOP when the MIE, and first few KEs occur. A major difference caused by a specific chemical/stressor may be the action about the MIE, because, in the end, harmful effects in the body will converge to some similar KEs that generate a tumor via cellular abnormalities. Hence, understanding the target chemical's structure, properties, and in vivo (similar) mechanism should be preferentially considered in the AOP, for assessment and prevention of risk and further therapeutic application.

\section{CONCLUSION}

As a conceptual framework, the AOP describes the intuitive understanding about the adverse effects of chemicals. The goal of the AOP is to accurately predict AOs caused by stressors. The AOP approach has emerged as a future-oriented alternative to the existing paradigms in the field of risk assessment. Although the AOP approach was first introduced for ecotoxicology risk assessment, it is continuously being developed for wide use in the overall risk assessment field. With concerted efforts to understand the effects of chronic toxic chemical exposure that can lead to cancer, the AOP applied to chemical carcinogenic risk assessment will be a very useful tool to predict carcinogenicity. Ultimately, based on these predictions, it could provide a breakthrough in cancer prevention.

\section{ACKNOWLEDGMENTS}

This study was supported in part by a grant (2017001970002) from the Korea Ministry of Environment, through "The Chemical Accident Prevention Technology Development Project". 


\section{CONFLICTS OF INTEREST}

No potential conflicts of interest were disclosed.

\section{REFERENCES}

1. Inter-Organisation Programme for the Sound Management of Chemicals (IOMC). Manual for the public health management of chemical incidents. Geneva, World Health Organization (WHO), 2009.

2. Bell J, Healey N. The causes of major hazard incidents and how to improve risk control and health and safety management: a review of the existing literature. Buxton, Health and Safety Laboratory, 2006.

3. Zheng F, Zhang MG, Song J, Chen FZ. Analysis on risk of multi factor disaster and disaster control in oil and gas storage tank. Procedia Eng 2018;211:1058-64.

4. Jefferson M, Chung PWH, Kletz TA. Learning the lessons from past accidents. London, IChemE Services, pp 217-26, 1997.

5. Oliveira PA, Colaço A, Chaves R, Guedes-pinto H, De-La-Cruz P LF, Lopes C. Chemical carcinogenesis. An Acad Bras Cienc 2007; 79:593-616.

6. Cohen SM, Arnold LL. Chemical carcinogenesis. Toxicol Sci 2011;120 Suppl 1:S76-92.

7. ChemSafetyPro. Chemical risk assessment: overview and examples. https://www.chemsafetypro.com/Topics/CRA/introduction to_chemical_risk_assessment_overview_principles.html. Accessed September 1, 2018.

8. Edwards SW, Tan YM, Villeneuve DL, Meek ME, McQueen CA. Adverse outcome pathways-organizing toxicological information to improve decision making. J Pharmacol Exp Ther 2016;356: 170-81.

9. Vinken M. The adverse outcome pathway concept: a pragmatic tool in toxicology. Toxicology 2013;312:158-65.

10. Ankley GT, Bennett RS, Erickson RJ, Hoff DJ, Hornung MW, Johnson $\mathrm{RD}$, et al. Adverse outcome pathways: a conceptual framework to support ecotoxicology research and risk assessment. Environ Toxicol Chem 2010;29:730-41.

11. Krewski D, Acosta D Jr, Andersen M, Anderson H, Bailar JC 3rd, Boekelheide $\mathrm{K}$, et al. Toxicity testing in the 21st century: a vision and a strategy. J Toxicol Environ Health B Crit Rev 2010;13: 51-138.

12. Clewell $\mathrm{H}$. Use of mode of action in risk assessment: past, present, and future. Regul Toxicol Pharmacol 2005:42:3-14.

13. National Research Council (US) Committee on Occupational Health and Safety in the Care and Use of Nonhuman Primates. Occupational health and safety in the care and use of nonhuman primates. Washington (DC), National Academies Press, 2003.

14. Carpenter DO, Arcaro K, Spink DC. Understanding the human health effects of chemical mixtures. Environ Health Perspect 2002;110 Suppl 1:25-42.

15. United States Environmental Protection Agency (U.S. EPA). Human health risk assessment. https://www.epa.gov/risk/human-health-risk-assessment. Accessed September 1, 2018.

16. Bessems JG, Loizou G, Krishnan K, Clewell HJ 3rd, Bernasconi C, Bois F, et al. PBTK modelling platforms and parameter estimation tools to enable animal-free risk assessment: recommendations from a joint EPAA--EURL ECVAM ADME workshop. Regul Toxicol Pharmacol 2014;68:119-39.

17. Zvinavashe E, van den Berg H, Soffers AE, Vervoort J, Freidig A, Murk AJ, et al. QSAR models for predicting in vivo aquatic toxicity of chlorinated alkanes to fish. Chem Res Toxicol 2008; 21:739-45.

18. United States Environmental Protection Agency (US EPA). Guidelines for exposure assessment. Washington, EPA, 1992.

19. Duffus JH, Nordberg M, Templeton DM. Glossary of terms used in toxicology. 2nd edition. Research Triangle Park, Pure and Applied Chemistry, pp 1153, 2007.

20. Sugimura T. Multistep carcinogenesis: a 1992 perspective. Science 1992;258:603-7.

21. Sugimura T. Nutrition and dietary carcinogens. Carcinogenesis 2000;21:387-95.

22. American Cancer Society. Known and probable human carcinogens. https://www.cancer.org/cancer/cancer-causes/generalinfo/known-and-probable-human-carcinogens.html. Accessed September $1,2018$.

23. International Agency for Research on Cancer (IARC). Agents classified by the IARC monographs, volumes 1-122. https:// monographs.iarc.fr/agents-classified-by-the-iarc/. Accessed September $1,2018$.

24. Kleinsmith LJ. Principles of cancer biology. London, Pearson Education, 2013.

25. Murti CK. Biological effects of chemical disasters: human victims. In: Bourdeau P, Green G, eds. Methods for assessing and reducing injury from chemical accidents. Chichester, Wiley, 1989.

26. Silins I, Högberg J. Combined toxic exposures and human health: biomarkers of exposure and effect. Int J Environ Res Public Health 2011;8:629-47.

27. Pletz J, Sánchez-Bayo F, Tennekes HA. Dose-response analysis indicating time-dependent neurotoxicity caused by organic and inorganic mercury-implications for toxic effects in the developing brain. Toxicology 2016;347-349:1-5.

28. Gollapudi BB, Johnson GE, Hernandez LG, Pottenger LH, Dearfield KL, Jeffrey AM, et al. Quantitative approaches for assessing dose-response relationships in genetic toxicology studies. Environ Mol Mutagen 2013:54:8-18.

29. Hernández AF, Tsatsakis AM. Human exposure to chemical mixtures: challenges for the integration of toxicology with epidemiology data in risk assessment. Food Chem Toxicol 2017; 103:188-93.

30. Organization for Economic Co-operation and Development (OECD). Users' handbook supplement to the guidance document for developing and assessing adverse outcome pathways. Paris, OECD Publishing, 2016.

31. Organization for Economic Co-operation and Development (OECD). Proposal for a template, and guidance on developing and assessing the completeness of adverse outcome pathways. Paris, OECD Publishing, 2012.

32. Tollefsen KE, Scholz S, Cronin MT, Edwards SW, de Knecht J, Crofton K, et al. Applying Adverse Outcome Pathways (AOPs) to support Integrated Approaches to Testing and Assessment (IATA). Regul Toxicol Pharmacol 2014;70:629-40.

33. European Chemicals Agency (ECHA). Weight of evidence. https://echa.europa.eu/support/registration/how-to-avoid-unnecessary-testing-on-animals/weight-of-evidence. Accessed September 


\section{$1,2018$.}

34. Villeneuve DL, Crump D, Garcia-Reyero N, Hecker M, Hutchinson $\mathrm{TH}$, LaLone CA, et al. Adverse outcome pathway (AOP) development I: strategies and principles. Toxicol Sci 2014;142:312-20.

35. Leist M, Ghallab A, Graepel R, Marchan R, Hassan R, Bennekou $\mathrm{SH}$, et al. Adverse outcome pathways: opportunities, limitations and open questions. Arch Toxicol 2017;91:3477-505.

36. Organization for Economic Co-operation and Development (OECD). Adverse Outcome Pathway Knowledge Base (AOP-KB). https://aopkb.oecd.org/background.html. Accessed September 1, 2018.

37. Organization for Economic Co-operation and Development (OECD). Society for the Advancement of Adverse Outcome Pathways (SAAOP). http://www.saaop.org/. Accessed September 1, 2018.

38. Organization for Economic Co-operation and Development (OECD). Adverse Outcome Pathways, molecular screening and toxicogenomics. http://www.oecd.org/chemicalsafety/testing/ adverse-outcome-pathways-molecular-screening-and-toxicogenomics.htm. Accessed September 1, 2018.

39. Pottenger LH, Schoeny R, Moore M, Simon TW. AFB1: mutagenic mode-of-action leading to Hepatocellular Carcinoma (HCC). https://aopwiki.org/aops/46. Accessed September 1, 2018.

40. Moore MM, Schoeny RS, Becker RA, White K, Pottenger LH. Development of an adverse outcome pathway for chemically induced hepatocellular carcinoma: case study of AFB1, a human carcinogen with a mutagenic mode of action. Crit Rev Toxicol 2018:48:312-37.

41. Pottenger LH, Schoeny R, Moore M, Simon TW. Tumorigenesis, hepatocellular carcinoma. https://aopwiki.org/events/378. Accessed
September 1, 2018.

42. Jarabek AM, Pottenger LH, Andrews LS, Casciano D, Embry MR, $\mathrm{Kim} \mathrm{JH}$, et al. Creating context for the use of DNA adduct data in cancer risk assessment: I. Data organization. Crit Rev Toxicol 2009:39:659-78.

43. Pottenger LH, Andrews LS, Bachman AN, Boogaard PJ, Cadet J, Embry MR, et al. An organizational approach for the assessment of DNA adduct data in risk assessment: case studies for aflatoxin B1, tamoxifen and vinyl chloride. Crit Rev Toxicol 2014;44: 348-91.

44. Moore MM, Heflich RH, Haber LT, Allen BC, Shipp AM, Kodell $\mathrm{RL}$. Analysis of in vivo mutation data can inform cancer risk assessment. Regul Toxicol Pharmacol 2008;51:151-61.

45. Sukowati $\mathrm{CH}$, El-Khobar KE, Ie SI, Anfuso B, Muljono DH, Tiribelli C. Significance of hepatitis virus infection in the oncogenic initiation of hepatocellular carcinoma. World J Gastroenterol 2016;22:1497-512.

46. Ravinayagam V, Jaganathan R, Panchanadham S, Palanivelu S. Potential antioxidant role of tridham in managing oxidative stress against aflatoxin-B(1)-induced experimental hepatocellular carcinoma. Int J Hepatol 2012;2012:428373.

47. Webster F, Lambert IB, Yauk CL. Chronic Cyp2E1 activation leading to liver cancer. https://aopwiki.org/aops/220. Accessed September 1, 2018.

48. Smith MT, Guyton KZ, Gibbons CF, Fritz JM, Portier CJ, Rusyn I, et al. Key characteristics of carcinogens as a basis for organizing data on mechanisms of carcinogenesis. Environ Health Perspect 2016;124:713-21.

49. Caro AA, Cederbaum AI. Oxidative stress, toxicology, and pharmacology of CYP2E1. Annu Rev Pharmacol Toxicol 2004:44:27-42. 